\title{
DESIGN AND DEVELOPMENT OF A PROTOTYPE FOR A WEB-BASED INTERFACE FOR ONLINE MATERIAL FOR TANZANIAN YOUTH
}

\begin{tabular}{|c|c|}
\hline $\begin{array}{c}\text { Chumo, } \boldsymbol{C} . \\
\text { Department of Anthropology } \\
\text { University of California, Davis } \\
\text { I Shields Avenue } \\
\text { Davis, CA } 94616 \text { USA }\end{array}$ & $\begin{array}{c}\text { Mjema, E.A.M. } \\
\text { Department of Engineering Management and } \\
\text { Entrepreneurship } \\
\text { University of Dar es Salaam } \\
\text { P.O. Box 35131, Dar es Salaam Tanzania }\end{array}$ \\
\hline $\begin{array}{l}\text { Ms Chumo is a research } \\
\text { assistant at University of } \\
\text { California, Davis interested } \\
\text { in youth participation in } \\
\text { international development. } \\
\text { She graduated from Mills } \\
\text { College in Oakland, } \\
\text { California, USA with a B.A. }\end{array}$ & $\begin{array}{l}\text { Prof. Mjema is a Mechanical } \\
\text { Engineer by professional. He } \\
\text { obtained hi B.Sc in } \\
\text { Engineering from the } \\
\text { University of Dar es Salaam, } \\
\text { M.Sc (Eng.) from the } \\
\text { University of Alberta Canada } \\
\text { and Dr.-Ing from the } \\
\text { University of Technology }\end{array}$ \\
\hline
\end{tabular}

\begin{abstract} that can be used by youth groups in Dar-es-Salaam.

\section{Introduction}

Youth represent the largest group of Internet users in Tanzania, yet they tend to use the web mostly for communication and entertainment (Chachage, 2001; Katunzi-Mollel, 2003; Nnafie, 2002), thus missing information with cultural and socio-economic value, such as educational and business information. When thinking about the enormous amount of information available on the Internet and its potential impact on economic and social development, one really wonders what prevents Tanzanian youth from accessing the valuable online information.
\end{abstract}

A prototype of a web-based interface for an online database was developed to be used by youth organizations in Dar-es-Salaam. A participatory approach involving secondary students in the identification of user interface requirements, in designing and testing the prototype was used. A questionnaire was designed and manned in seven secondary schools in Dar-es-Salaam to estimate the Internet usage. Interviews were conducted to countercheck the questionnaire responses. The interview and the questionnaire helped to come up with a set of user requirements for the web-based interface of an online information search. From the specifications of the user requirements the author was able to create a youth-friendly web based prototype

There is not much research to explain reasons that hinder youth from accessing valuable information from the internet. Therefore, there is a need to carry out studies that will establish decisive factors for high level web usability. An in-depth look at the challenges youth face when navigating informational web sites will inform future web developers as to the appropriate scenario for providing youth with useful and easily accessible online content. It is imperative to carry out research on web usability in order to assess factors that prevent the largest group of the population from accessing useful material from the Internet, and consequently to produce a set of web interface requirements that will improve the user friendliness of web access.

It is purported that language, cost, and lack of training as well as supervision contribute to the limited use of the Internet (Katunzi-Mollel, 2003; Norton, 2003). In that aspect, an in-depth research on the implications of web design affecting usability for Tanzanian youth will give a hint as to 
whether customized web interfaces or increased Internet training presents the best solution.

This study first analyzes the skills Tanzanian youth have with search interfaces of common online information sources to produce a set of interface requirements that will be used to create and test the search function of a web site prototype. Finally a model web prototype is designed, developed and tested to give an indication as to whether the problem is within the design of the web sites or the problem lies in another area.

The primary objective of the research is to develop a prototype of a web-based interface for an online database of youth organizations in Dar-es-Salaam. The web design is based on an analysis of the experiences Tanzanian secondary students have in navigating web sites. Specific objectives are to:

i) identify a set of user interface requirements appropriate to Tanzanian secondary students for searching an online information resource,

ii) create the prototype of a web-based interface for an online database of youth organizations in Dar-es-Salaam, and

iii) evaluate the web site prototype for its usability and appropriateness for secondary students.

\section{The Situation}

This section covers three areas affecting Tanzanian youth: (1) the potential of Internet use for socioeconomic development, (2) the impact of web usability for universal Internet access, and (3) the usability of interfaces for online information resources.

\section{The Potential of Internet Use}

Forming $85 \% \mathrm{t}$ of the worldwide population between ages of 15 and 24 years, youth in developing countries play a critical role in applying information to development (International Center for Research on Women [ICRW], 2001; Mihyo and Ogbu, 2000; Ministry of Communications and Transport [MCT], 2003). In Tanzania, where the median age is 17.4 years, youth are a large part of the population and are greatly affected by poverty, as in other developing countries. High rates of HIV/AIDS and unemployment are two factors that keep youth in Tanzania poor (Youth Development Network [YDN], 2002), and, consequently, prevent them from using the Internet. HIV-positive youth often face stigma barring them from educational and employment opportunities. Unemployed and uneducated youth lack both the financial means and ability to access the Internet. HIV/AIDS and unemployment are factors of poverty which increase "digital inequality" of youth in Tanzania and the developing world (DiMaggio et al., 2004). Recently, however, the Tanzanian government's national information and communication technology (ICT) plan placed computer education at the top of its priorities, and secondary schools and universities are concurrently building technological resources and revising curricula to develop learning of ICTs (MCT, 2003), as ICT skills are accepted as central to local economic development (Mhayaya, 2003).

Apart from the barrier created by poverty between youth and Internet access, youth still constitute the largest age group of Internet users in Tanzania (Chachage, 2001; Katunzi-Mollel, 2003; Luambano, 2004; Nnafie, 2002). However, the main motivation behind internet use is communication and entertainment (Chachage, 2001). It was established that youths mostly use the Internet for email, music downloading, instant messaging, games, and pornography.

It is believed that developing countries struggle fruitlessly because they lack up-to-date information while competing on the global market with developed countries that have modern technology (Beute, 1992). There is a strong correlation between economic development and technological advancement (Bogojevic and Lazovic, 2002). Jaimes et al. (2003) suggest four research areas, each of which could integrate the Internet: resource sharing, distance learning, teaching tools, and the cultural impact of technology.

\section{The Impact of Web Usability for Universal Internet Access}

Web usability makes Internet access easier for typical web users, by methods such as setting standards for navigation, text, links and the use of color. Web usability balances the needs of the user with the task flow, and with system restrictions for menus, graphics, and linked documents (Galitz, 2002; Nielsen, 1993). However, web usability is not always practiced with the interests of the end-users in mind. Increased accessibility on commercial web pages results in more consumers for businesses that sell goods online (Loiacono, 2003; Nielsen, 2005b). Challenges with simplifying web usability include standardization, which is not always possible, because users and their tools vary, while few web 
sites offer instructional assistance (Galitz, 2002). Web usability is a branch of Human Computer Interaction (HCI), a discipline that may allow developing countries to more effectively compete in the global economy by tailoring ICT tools to the needs of the people who use them (Cogburn, 2003). The following life cycle of web usability can be applied to the localization of interfaces and content used in the transfer of technology to developing countries:

i) Requirements analysis, which involve building user profiles and task analysis in order to create a picture of user knowledge and experience with a desired task.

ii) Design and testing, which is an iterative process in which users participate. Simple prototypes out of paper, for example, are useful for quickly testing design ideas.

iii) Once the design and testing process narrows down a working product the production team releases the final design for feedback (Mayhew, 1999).

Perhaps the greatest potential of web usability is its accommodation for different types of users, such as those with disabilities, from various cultures, and of different ages. Recently the need for web usability received media exposure with the World Summit on the Information Society's "World Summit Award" for exceptional web content (Jaimes, 2006). First, regarding disability, there are several standards in place, a commonly cited example being the World Wide Web Consortium's Web Accessibility Initiative (W3W/WAI) (Hofstader, 2004; White, 2003; Boldyreff, 2002; Cudd and Oskouie, 1996). Standards that will assist the disabled are necessary not only for existing technologies, but for new technology as well, which advances quickly (Carter and Markel, 2001). As a testament to the lack of attention African countries have paid to web accessibility, the International Center for Disability Resources on the Internet (2006) hosts a database of web accessibility standards by country, in which there are no listings for countries in Africa. Considering the existence of web usability standards for disabilities a case can be made for accessibility standards for other types of users.

Web interface customization for users from developing countries is a research area with potential for expansion and a major focus of this research. Where web usability for disability must accommodate users' ability to move, hear, see and think (Carter and Markel, 2001), web usability for developing countries must account for not only outdated computers and slow Internet connections, but for cultural traits, such as language, and lack of formal education, as well. A growing body of literature in HCI examines the adaptation of technology for developing countries (Dray, Siegel, and Kotzé, 2003; Ford and Gelderblom, 2003; Jaimes et al., 2003; Hole-in-the-Wall Education, Ltd. [HIWEL], 2005; Kotze, 2002; Mihyo and Ogbu, 2000; Walton, Marsden, and Vukovic, 2001; Walton and Vukovic, 2003; Yeo, 1996). In Tanzania, studies note the need to include Swahililanguage content, and account for slow connection speeds and a lack of Internet training (Chachage, 2001; Katunzi-Mollel, 2003; Nnafie, 2002). Therefore, not only do the language of the content and lack of training affect accessibility of online information, but the visual, interactive, and internal structure of web sites does as well.

Most current web design in Tanzania is neither based on locally developed techniques nor on local user testing. All web design books found during an informal survey of book shops in Dar-es-Salaam were published outside of Africa, and 90 percent of Internet café users never use the Internet for web design (Nnafie, 2002). When a web site from outside of Tanzania is adapted to Tanzanian youth it should be considered a new interface and undergo a thorough usability test, including web sites where content translation into Swahili is the only adaptation (Nielsen, 1990). Haasbroek (1992) remarked that many of the difficulties in using advanced technology from developed countries experienced by work forces in South Africa and other African countries are socio-cultural in nature, requiring both "intelligent interfaces" and training (p. 826). A government project created a user profile for a web interface for adults in a rural area of Tanzania showing that color choices, and the balance between text and images are important considerations (COSTECH, 2005b). When designing culturally sensitive user interfaces, some researchers advocate going beyond objective considerations of culture, such as language, icons, and symbols, to subjective considerations, which include values, ethics, and morals (Ford, 2003). It is not yet known whether the fact that web design is based on western standards influences web site usability for Tanzanian youth.

A web site with a design that is sensitive to the unique situation of Tanzanian youth might take into account their level of computer skills, reading ability in the language on the web site, and include 
graphics that are culturally significant. To reach inner city youth in the United States, White and Lester (2001) suggested using hip hop music to encourage youth to use the Internet. Hip hop, a genre with which many inner-city youth identify, could be used to send youth messages about the advantages of Internet use (White and Lester, 2001). However, the challenge of promoting effective Internet use replaces the challenges of getting youth online. For youth who use the Internet, reading level and attention span are common barriers (Nielsen, 2005c; Kikuchi et al., 2002). In fact, Kikuchi et al. (2002) found a strong correlation between a child's reading level and level of interest in the online content tested. However, regardless of a child's reading level, user involvement is crucial to the web design process and can have an impact on both the initial concept and the details of the interface (Harrison, Zappen, and Adali, 2005).

\section{The Usability of Interfaces for Online Information Resources}

Browsing involves exploration around a topic, searching for specific information, and serendipity. Common problems associated with browsing include disorientation and the chance that the user may find nothing of interest (Carmel et al., 1992). Site structure should help users find what they want, but is not always effective (Velasquez et al., 2003). Lessons learned from the way a user browses can be helpful in improving web design. Hijikata (1999) estimated the degree of user interest in web pages by observing mouse behavior during browsing, such as selecting text, scroll speed and circling the mouse, while Velasquez et al. (2003) restructured a web site based on the navigational trends of observed users.

When browsing fails to produce what the user wants, the user often resorts to available search tools. Nielsen (2001) articulated several search interface guidelines tested in developed countries: simplicity, accommodation for user input error, and prioritization of search results. The latter is important because most users do not look past the first page of results (Nielsen, 2004). A standard practice in web design is a search input interface that consists of a text label, user input box, and button to start the search. Nielsen (2001) argued that this design is more usable than 'advanced' searches, which users often do not know how to use. Wang and Kitsuregawa (2001) clustered search results based on URLs, in order to make the results easier to read.
Although there are practical standards for the interfaces of online informational resources, there is no proof that these standards are the best option for Tanzanian youth, who are members of a culture that did not originate web usability standards and have little online experience. The literature describing how users adapt to new interfaces based on their mental model, or cumulative experience with other types of interfaces (Nielsen, 2005; Norton, 2003), is inapplicable to users with little or no Internet experience. The construction of a mental model for online browsing by Tanzanian youth requires alternate means. Searching and browsing are common human behaviors outside of the Internet context, and lessons learned from people's searches in daily life may apply to the online setting.

The goal of this research is to record the experience and behaviors of Tanzanian youth with web interfaces and to present a model interface. It is intended that the results of the study will offer recommendations for future research on web usability such as the personalization of web interfaces (Sugiyama, Hatano, and Yoshikawa, 2004; Teevan, Dumais, and Horvitz, 2005), for the development of Internet training curriculum, and for web designers of youth-friendly web sites in Tanzania.

\section{Methodology \\ Participatory Design}

The design technique was based on participatory research methods, engaging youth in the prototyping process. Participatory design increases "respondent validation" (Leedy and Ormrod, 2005), whereby respondents evaluate the results of data collection. Go et al. (2000) sought user participation in web design in order to generate a common technical vocabulary between users and designers. Starting with a concept of the web site, student responses shaped every stage of development in this research project. During all parts of the design phase, student design team members observed and practiced web design techniques, including concept planning, paper and web-based prototyping, and user testing. By the time the last prototype had been completed, design team members had developed the necessary vocabulary and perspective to speculate on the impact of this design on their peers.

The design team was de-centralized with participants from two different schools. Two students at Tegeta High School and three students at Jitegemee Secondary School made up the design team. The author visited design team members at 
both schools to get feedback before testing. After getting feedback the author tested the prototype at Jitegemee Secondary School with the help of the design team at that school. Teachers coordinated and supervised the testing session, which took place during free time.

\section{Web Usability Test}

The above approach to participatory design was used in combination with standard usability testing techniques. Web usability testing requires that the evaluator take into consideration the purpose of the site, scenarios for users accessing the web site, and profiles of users (Kantner and Rosenbaum, 1997). Usability test also requires an objective, a representative sample, a representative work environment, observation and interrogation, the collection of quantitative and qualitative data, and, finally, recommendations for improvements (Prescott and Crichton, 1999). The author chose the representative sample from secondary school students in Dar-es-Salaam. The test took place in an Internet café at a secondary school. Students almost exclusively go online in Internet cafés, since school computer labs and homes rarely have Internet access. Testing sessions were set up either with youth at individual computers or with a group at a single computer.

All parts of the design process included observation and interrogation. During user requirements gathering and paper-prototyping, the design team and the author interacted informally, discussing the work together. The author also posed clarifying questions and made observations. During the testing session, the author observed participants while they thought aloud. After the testing session the test participants and the author discussed the test. Froekjaer and Hornbaek (2005) called the combined approach of think-aloud observations and discussion "cooperative usability testing." Since participants find think-aloud difficult while performing unfamiliar tasks, they appreciate an opportunity to clarify their thoughts in a discussion afterward. Froekjaer and Hornbaek (2005) also noted that participants like discussion because they are able to gauge how their contributions impact the project. Quantitative data include the actions participants made during the guided tasks, such as the number of times participants visited a specific web page. Qualitative data include the participants' impressions of the web site's attractiveness. Discussions with the testing pool were similar to those with the design team. Participants gave feedback and responses to the clarifying questions from the author. The way they expressed themselves allowed the author to see whether or not they understood what the interface was trying to convey, and to see if their concept of the interface matched the intended concept, in the sense of Norman (1988). The conversations let the author probe into the motivations behind participants' actions and design improvements to the prototypes.

\section{User Requirements}

Prior to meeting with the design team, the author conducted a questionnaire and interviews on web use by youth. Using the resulting data, the author created a list of requirements for the user interface of the search function and related components of the web site, which were presented to the design team for feedback.

\section{Results and Discussion of Questionnaire}

Prior to the participatory web design phase, a total of 868 questionnaires were completed by the students from seven secondary schools from all three districts in Dar-es-Salaam, whose the ages were between 15 and 24 years. 68 of the questionnaires were discarded, because the respondent's age was outside of the 15 to 24-year range, the respondent did not indicate an age, or the handwriting was illegible.

The aim was to know the familiarity of the participants with the computer. It was revealed that the majority of the students were familiar with modern information and communications technologies $(78.10 \%)$ and they use computer frequently $(59.6 \%)$. However, it was also established that the majority of students have not sought online information on youth groups in Tanzania (59.25\%). Regarding the method they use to find specific information, it was indicated that if they have any problem with the computer, they are mostly likely to search for information by asking others for help (42.5\%), using the Internet (37.6\%), and using a directory (15.7\%). When using a directory students are most likely to look up youth groups by name (36.3\%), location $(26.1 \%)$ and activity type $(38.1 \%)$.

Regarding the training in computing, it was established that the students learned to use the Internet in different ways and for different purposes. Though most students use the Internet alone $(54.7 \%)$, a sizable number use the Internet with another person (32.5\%). Students learned to use the Internet from a friend (36.7\%), in a schoolrelated capacity $(25.2 \%)$, from a relative $(21 \%)$, or from staff at an Internet café (17.1\%). 


\section{Paper-based Prototype}

Using the set of approved requirements, the author created a prototype of the interface design on paper, which the design team reworked until they reached mutual agreement. The prototype included all the steps involved in browsing the web site, from when a user enters the web site, until the user views database entries. Low-tech prototyping with paper is cost- and time-effective (Kaplan et al., 2004; Snyder, 2003). Grady (2000) noted that paper prototyping works because the pieces are easy to move, it does not require computer literacy, and it invites feedback from participants who may be more willing to criticize an obviously rough draft. Grady (ibid.) also noted that paper prototypes are effective because they let users identify obvious problems such as the nomenclature of web pages and the conceptual model of the entire web site.

\section{Web-based Prototype}

The results of the paper-based prototype guided the author in constructing the first web-based draft of the interface. The design team critiqued the first web-based prototype until they settled on a model that they wanted other students to test. At this point the first group of students outside of the design team was tested. Then, the author re-designed the prototype based on the responses of the first testing pool. Nielsen (2005b) observed that prototyping and usability testing never finish, because technological innovation happens quickly and user interests change over time. However, in the interest of time, the author limited this study to three web-based prototypes. The third and final prototype ended the five-phase design process.

\section{The Prototype}

Critical elements of the final web-based prototype are based on design decisions and evaluations for each prototype, which the author evaluated using the participatory approach with the students. Some of these elements contradict previous studies on web usability. This list provides an explanation of the elements in web design that were necessary for a readily comprehensible and easy to use web site for Tanzanian secondary students, contrary to conventional web design.

1. A linear site structure with links that guide the user from one page to the next limits user disorientation within the web site more than hierarchical site structures where users have more options.

2. Links that trigger between the time a user presses and lifts the mouse button (on-mousedown) are acceptable over links that trigger after a user lifts the mouse button (on-mouseup), because when using the latter many students do not know to lift the mouse and thus never activate the link.

3. Duplication of links between the navigation bar and "next" and "back" buttons in a linear site structure is necessary in order to both provide a visual tool to identify a web page's place in the linear scheme and to provide experienced Internet users an alternative to the guided linear flow.

4. In spite of literature that warns of displaying too much text for users to read, instructions on using links and browser functions are imperative for new users who have never touched a mouse or navigated the Internet. Respondents approved of the amount of text on each page.

5. The location of the navigation bar at the bottom of each page rather than at the top, emphasizes the visibility of the "next" and "back" buttons located closer to the center of the page and may encourage new users to use the upper links and benefit from the linear page flow.

6. The Arial font hard-coded into every page ensures that a browser's default font does not resize the page layout, which must fit within the standard $600 \times 800$ resolution screens common in Tanzania and maintains the text's position above the scroll limit for users who do not know how to use the scroll bar.

7. The web site only needs to be functional in Internet Explorer, since that is the web browser that the vast majority of secondary students use.

User interface requirements that fall within established web design norms include the following:

1. Images may be useful for conveying information, but create slow page loads in a region with slow connections.

2. Page design must appeal to the youth perception of "cool."

It is hoped that the above user interface requirements assist web designers in creating usable web sites for Tanzanian youth.

The final prototype (Appendix 1) is the result of by of a five-phase design process (user requirements, paper prototyping and three web-based prototypes), which followed data collection by questionnaires, 
interviews and observations. The preceding phases largely determine the outcome of the final prototype. Challenges that students face with the design and navigational structure of online information resources were identified and addressed through the questionnaires, interviews and summarized in the user interface requirements. For example, students reported in the questionnaires that they would look up youth groups in directory by activity type first, then by name and location. This information shaped the design of the search page, where each option is presented clearly so that each user may view youth groups sorted by her or his preferred category. Also, in an attempt to define "youth-friendly" web design the design team vetoed the first prototype. The testing pool also helped define "youth-friendly" web design, with their preference for a black, white and grey color scheme and several other preferences outlined in the user interface requirements.

\section{Limitations}

The main limitations were difficulty in eliciting clear or candid responses from the participants, the lack of electronic recording equipment, slow transportation and the lack of a final testing session. First, during the every stage of data collection the author suspected bias entered the data because of the eagerness of youth to be polite to and not criticize a visitor. Taking this potential bias into account, honest reactions to the prototypes may not been as positive as the data the author collected.

The author recommends that future studies with Tanzanian youth, and possibly all test groups, make every precaution to solicit natural responses. Second, there were no video or audio recording equipment with which to record the interviews and design process. Therefore, the author's hurried note taking may have compromised data from the interviews and design process.

In addition to the above limitations, there were a number of logistical challenges as well. Some of the same technological challenges that limit youth access to the Internet curtailed the author's ability to use computers for the research; these include electrical outages, Internet failure and slow connections and climate.

\section{Practical Applications and Directions for Future Research}

There are a number of areas in which to apply the results of this research, as well as directions for further research. However, most pressing is the need for a comparative study of novice users in the
West and in Tanzania. The seven user requirements listed above contradict conventional web design, not necessarily web design for novice youth in the West. A comparative study could follow a procedure similar to the user requirements gathering phase of this study. The author recommends that the study involve interviews, guided tasks, and observations, in order to collect comparable data on specific user behaviors. These phases would focus on the seven contradictions, in addition to recording new behaviors. For example, in order to select a link, do all youth hold down the mouse expecting the link to trigger before they release the mouse button? The sample would be chosen from a parallel demographic in each location. This proposed study would help in determining whether the results of the current study are unique to Tanzanian youth or characteristic of a wider sample of youth.

Other future steps include the following:

- Development of an alternative interface to the web site for more experience users.

- In-depth research into each of the web design areas touched by this study: color and layout aesthetics, search interfaces in search engines, and instructions on Internet use that are embedded into web sites.

- Application of the research outcomes to guide software interface development of educational materials, web design classes, and business solutions.

\section{Conclusion}

The main objective of this research was to develop the prototype of a web-based interface for an online database of youth organizations in Dar-es-Salaam. A set of user interface requirements for online information resources based on an analysis of the experiences Tanzanian secondary students have navigating web sites was first developed. Then a web site prototype was developed using a participatory approach. The prototype was tested in some secondary schools in Dar es Salaam and showed high web usability.

When considering the context of web usability for youth in Tanzania, the author addressed three topics: the potential of Internet use for socioeconomic development, the impact of web usability for universal Internet access, and the usability of interfaces for online information resources. Regarding the first topic, this study expands the Internet's potential to improve socio-economic status of youth in Tanzania by customizing web interfaces of online information resources. The 
results of the testing session address the second and third topics by evaluating the usability of the web interface prototype in order to see if the development of user interface requirements and participatory web design increase user access to the site.

Two additional outcomes of the study are that the student participants learned Internet and computer skills and the study provided data for the debate over Internet customization versus training. First, interviews exposed participants to new web sites and navigational skills, and members of the design team practiced the planning and testing phases of web development.

The second additional outcome is that this research falls within the ongoing debate over prioritizing Internet training or customization for new or novice users in developing countries. While the author collected data for customization throughout the questionnaire, interview, and observation phases, the author employed both training and customization in the design process. Specifically, the design team learned web design techniques in order to create a user interface that would be easier to use, both for themselves and for Tanzanian youth at-large.

The prototypes and user interface requirements represent one of the few web usability studies done with youth in Africa. Using standard web design technology developed outside of Africa, the application of the results of this research project will make web access easier and more attractive for youth in Tanzania. The final prototype developed is shown on Appendix 1.

\section{Literature}

Beute, N., (1992). Technology education for development. Proceedings from Africon '92: Africon Conference in Africa.

Bogojevic, D. and Lazovic, S., (2002). A telecommunications development model for developing countries. Proceedings from Africon '02: $6^{\text {th }}$ Africon Conference on Africa.

Boldyreff, C. ,(2002). Determination and evaluation of web accessibility. Proceeings from WETICE '02: Eleventh IEEE International Workshops on Enabling Technologies: Infrastructure for Collaborative Enterprises.
Carmel, E., Crawford, S., and Chen, H., (1992 Sept/Oct). Browsing in hypertext: A cognitive study. IEEE Transactions on Systems, Man, and Cybernetics, 22(5).

Carter, J. and Mike M., (2001 Dec). Web accessibility for people with disabilities: An introduction for web developers. IEEE Transactions on Professional Communication, 44(4).

Chachage, B. L., (2001). Internet cafés in Tanzania: A study of knowledge and skills of endusers. Information Development, 17(4).

Cogburn, D. L., (2003 Mar/Apr). HCI in the socalled developing world: What's in it for everyone? Interactions. 10, 80-87.

Commission for Science and Technology, (2005a Jan). Guidelines for development of internalised tools for Internet access. Government of the United Republic of Tanzania.

Commission for Science and Technology, (2005b Mar). Progress report: Appropriate tools for Internet access. Government of the United Republic of Tanzania.

Cudd, P.A. and Oskouie, R., (1996). Combining HCI techniques for better user interfacing." Proceedings from IEE Colluquium on Interfaces - The Leading Edge. London, UK.

DiMaggio, P., Hargittai, E., Celeste, C. and Shafer, S., (2004). From unequal access to differentiated use: A literature review and agenda for research on digital inequality. In K. Neckerman (Ed.), Social Inequality. New York, NY: Russell Sage Foundation.

Dray, S. M., Siegel, D. A., Kotzé, P., (2003 Mar/Apr). Indra's net: HCI in the developing world. Interactions. 10, 28-37.

Ford, G. and Gelderblom, H., (2003). The effects of culture on performance achieved trhough the use of human computer interaction. Proceedings from SAICSIT '03: Annual Conference of the South African Institute for Computer Scientists and Information Technologists.

Frokjaer, E. and Hornbaek, K., (2005). Cooperative usability testing: Complementing usability tests with user-supported interpretation sessions. Extended abstracts on human factors in computer systems. Portland, OR. 
Galitz, W. ,(2002). The essential guide to user interface design. New York, NY: John Wiley and Sons, Inc.

Gee, K.,(2001). The ergonomics of hypertext narrative: Usability testing as a tool for evaluation and redesign. Journal of Computer Documentation, 25(1), 3-16.

Gilutz, S., (2003). Children's online interfaces: Is usability testing worthwhile? Proceedings from IDC '03: Interaction Design and Children, pp. 143-145.

Grady, H. M. ,(2000). Web site design: A case study in usability testing using paper prototypes. Proceedings from the $18^{\text {th }}$ Annual Conference on Computer Documentation. 39-45.

Go, K., Takahashi, T., and Imamiya, A., (2000). A case study on participatory redesign of web site with scenario-based techniques. Proceedings from ICPADS '00: Seventh International Conference on Parallel and Distributed Systems.

Haasbroek, J.L., (1992). The challenges of utilizing intelligent human-computer interface technology in South Africa and other African developing countries. Proceedings from the IEEE International Conference on Systems, Man and Cybernetics.

Harrison, T.M., Zappen, J.P., and Adali, S., (2005). Building community information systems: The connected kids case. Computer, 38(12).

Hijikata, Y.., (1999). Estimating a user's degree of interest in a page during web browsing. Proceedings from the IEEE International Conference on Systems, Man, and Cybernetics.

Hoepfl, M. C., (1997). Choosing qualitative research: A primer for technology education researchers. Journal of Education Technology, 9 (1).

Hofstader, C., (2004). Internet accessibility: Beyond disability. Computer. 37(9).

Hole-in-the-Wall Education, Ltd., (2005). Minimally invasive education for mass computer literacy, New Delhi, India: S. Mitra. Retrieved September 7, 2006 from http://www.hole-in-thewall.com/docs/Paper01.pdf.

International Center for Disability Resources on the Internet. (2006). Global legal and policy resources. Retrieved September 7, 2006 from

http://www.icdri.org/

Global\%20Legal\%20Resources/global lega 1 resources.htm.

International Center for Research on Women. (2001 Dec). The critical role of youth in global development. Retrieved September 6, 2006 from

http://www.icrw.org/docs/Youth\%20in\%20

Dev_Issue\%20Brief_2001.pdf

Jaimes, A., (2006). Human-centered multimedia: Culture, deployment, and access. IEEE MultiMedia. 13(1), 12-19.

Jaimes, A, Kinshuk, and Sow, D., (2003). Technology for education in developing countries: A forward. Proceedings from ITRE '03: International Conference on Research and Education. Newark, NJ.

Kantner, L. and Rosenbaum, S. (1997). Usability studies of WWW sites: Heuristic evaluation vs. laboratory testing. Proceedings from SIGDOC '97: Conference for the Special Interest Group for Design of Communication.

Kaplan, N., Chisik, Y., Knudtzon, K., Kulkarni, R., Moulthrop, S., Summers, K., (2004). Supporting sociable literacy in the international children's digital library. Proceedings from IDC '04: Interaction Design and Children.

Kikuchi, H., Kato, H. and Akahori, K., (2002). Analysis of children's web browsing process: ICT education in elementary schools. Proceedings from ICCE '02: International Conference on Computers in Education.

Katunzi-Mollel, K. R. U., (2003). An examination of patterns of access and use of the Internet by youth. (Dissertation, University of Dares-Salaam, 2003).

Kotzé, P., (2002). Directions in HCI education, research, and practice in southern Africa. Proceedings from CHI '02: Conference on Human Factors in Computer Systems, Minneapolis, MN.

Leedy, P. D. and Ormrod, J. E., (2005). Practical research: Planning and design. Upper Saddle River, NJ: Pearson Education, Inc.

Loiacono, E. T., (2003). Improving web accessibility. Computer. 36(1). 
Luambano, I., (2004). Internet use by students of the University of Dar-es-Salaam. (Dissertation, University of Dar-es-Salaam, 2004).

Mayhew, D. J., (1999). The usability engineering life cycle. San Francisco, CA: Morgan Kaufmann Publishers, Inc.

Mhayaya, S. G., (2003). A study of the potential usage of ICT (E-government) in improving efficiency and effectiveness of 'executive functions' of the government including delivery of public service: case of Tanzania. (Dissertation, University of Dar-es-Salaam, 2003).

Mihyo, P. B. and Ogbu, O., (2000). Youth leadership program for Africa. In P. B. Mihyo and O. Ogbu (Eds.), African youth on the information highway: Participation and leadership in community development (130). International Development Research Centre.

Ministry of Communications and Transport (2003). National information and communications technologies policy. Government of the United Republic of Tanzania.

Nielsen, J., (1990). Usability testing of international interfaces. In J. Nielsen (Ed.), Designing user interfaces for international use. New York, NY: Elsevier Science Publishers.

Nielsen, J., (1993). Usability engineering. San Diego, CA: Academic Press, Inc.

Nielsen, J., (2001). Search: Visible and simple. Alertbox. http://www.useit.com/alertbox.

Nielsen, J., (2004). Top ten mistakes in web design. Alertbox. http://www.useit.com/alertbox.

Nielsen, J., (2005). Mental models for search are getting firmer. Alertbox. www.useit.com/alertbox.

Nielsen, J., (2005b). Usability: Empiricism or ideology? Alertbox. www.useit.com/alertbox.

Nielsen, J., (2005c). Usability of web sites for teenagers. Alertbox. www.useit.com/alertbox.

Nnafie, I., (2002). Internet cafés in Dar-es-Salaam: Problems and opportunities. (Dissertation, University of Technology, Eindhoven, 2002).
Norman, D. A., (1988). The design of everyday things. New York, NY: Basic Books.

Norton, D., (2003). Rainbow usability: Customization vs. training in developing countries. Interactions, 10, 9-12.

Prescott, J. and Crichton, M., (1999). Usability testing: A quick, cheap, and effective method. Proceedings from SIGUCCS '99: Conference for the Special Interest Group on University and College Computing Services. Denver, CO.

Snyder, C., (2003). Paper prototyping. San Francisco, CA: Morgan Kaufmann Publishers.

Sugiyama, K., Hatano, K., Yoshikawa, M., (2004). Adaptive web search based on user profile constructed without any effort from users. Proceedings from WWW2004: Thirteenth International World Wide Web Conference. New York, NY.

Teevan, J., Dumais, S. T., Horvitz, E., (2005). Personalizing search via automated analysis of interests and activities. Proceedings from SIGIR '05: $28^{\text {th }}$ Annual International Conference on Research and Development in Information Retrieval. Salvador, Brazil.

Thompson, K. E, Rozanski, E. P., and Haake, A. R., (2004). Here, there, anywhere: Remote usability testing that works. ACM's SIGITE '04. October 28-30, 2004, Salt Lake City, Utah, USA. 132-136.

Velasquez, J.D., Yasuda, H., Aoki, T., and Weber, R., (2003). Acquiring knowledge about user's preferences in a web site. Proceedings from ITRE '03: International Conference on Information Technology, Research and Education.

Walton, M., Marsden, G., and Vukovic, V., (2001). 'Visual literacy' as a challenge to the internationalization of interfaces: A study of South African student web users. Proceedings from CHI-SA 2001: Second Annual South African Human-Computer Interaction Conference.

Walton, M. and Vukovic V., (2003). Cultures, literacy and the web: Dimensions of information 'scent.' Interactions, 10, 64-71.

Wang, Y. and Kitsuregawa, M., (2001). Use linkbased clustering to improve web search results. Proceedings from WISE '01: 
Second International Conference on Web Information Systems Engineering.

White, B.,. (2003). Web accessibility, mobility, and findability. Proceedings of LA-WEB'03: First Latin American Web Congress.

White, S; and Lester, W.F., (2001). Cultural relevance: Hip-hop music as a bridge to the digital divide. Proceedings of the $34^{\text {th }}$ Hawaii International Conference on System Sciences.

World Summit on the Information Society. World Summit Award winners 2005. Retrieved September 7, 2006 from http://www.wsisaward.org/index.php?folder=264andarticle $=$ 450 .

Youth Development Network (2002). Tanzania final country report. Retrieved September 7, 2006 from http://www.ydn.org.za/modules.php?name= VStuffandfile $=$ indexandfunc $=$ ShowStuffan $\mathrm{dSID}=12$

Yeo, A., (1996). Cultural user interfaces: A silver lining in cultural diversity. SIGCHI Bulletin 28(3): 4-7.

\section{Appendix 1: Final Web-based Prototype}

\section{Template}

This prototype incorporates recommendations from the first formal usability test. The following is a description of the design.

- All pages display best with a screen resolution of $600 \times 800$ in Internet Explorer, the most common set-up in Tanzania's Internet cafés. Most of the content is above the scroll limit because many users do not know how to use the scroll bar.

- The black title bar on every page serves to identify the web site apart from other sites on the Internet.

- Each page has a unique title, which is in the same location on every page to help with site recognition.

- The navigation bar is for users who are familiarwith the Internet. It also functions as a site map or "breadcrumb" by showing users where they are, where they have been, and where they are going.

- All links trigger "onMouseDown," as soon as the user pushes the mouse button and before lifting it up to accommodate users who unknowingly click and hold links.
- There are few images due to slow page loads, and no image map links, so that links will be consistent.

- There are no indications to "click here" with an arrow to a link, since users did not know where to click.

- The link color is specified by the browser, so they may be more likely to see colors they are familiar with.

- All links have a title that appears when the mouse hovers over the link, in order to clarify navigation.

- There are no graphics with text inside, in case the browser does not enable images or in case the language must be translated.

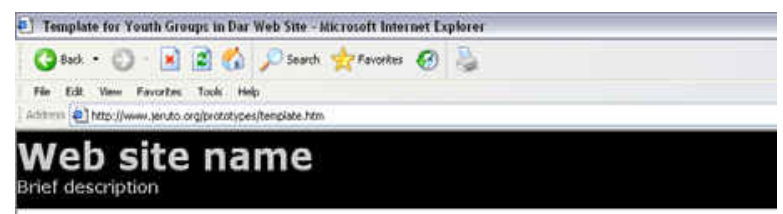

\section{Page Title}

Content, i.e. text, tables and links

The font is Arial, for which users showed a preference. There are few colors. The background and foreground colors contrast, which helps with reading. Users showed a preference for black, grey, and white.

\section{Home Page}

- The welcome page (or "splash" page) of prototype 2 was discarded since there is no choice of languages.

- The page title at the top of the browser window corresponds to the in-text page title.

- The home page is distinct from other pages as the root of navigation by using "Welcome!" as the heading and by implementing the upperright text box with a description of the site.

- The "next" and "back" links give the site a linear flow, as an alternative to the navigation bar for users who are unfamiliar with standard site architecture.

- The usability test of the second prototype indicated that users need help with using the mouse and links. The home page has 
instructions for users, so that they access help as soon as they enter the web site.

- There are no links to the current page, in case users expect a link to the current page to lead to a different page.

The image has alternative text, "Mouse," in case the browser does not enable images.

\section{About Page}

The about page has two columns of content because one column would not fit above the scroll line.

The in-text link, "BACK to previous page," is for users who are not aware of the browser's "Back" button.

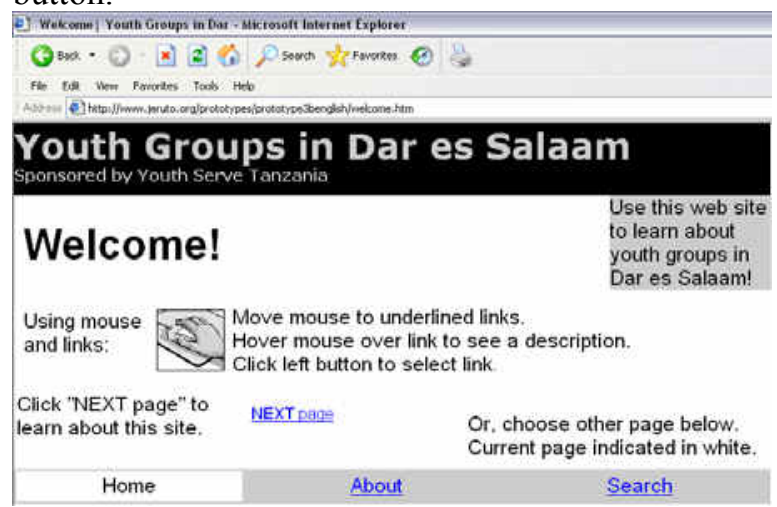

\section{Search Page}

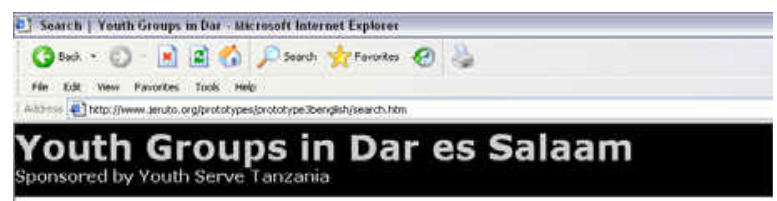

\section{Search Page}

Click on a link to see an entire list of youth groups or sections:

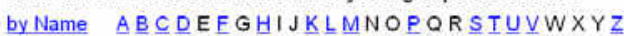

by Ward ABCDEFGHIJKLMNOPQRSTUVWXYZ

by Activity Arts Community Football

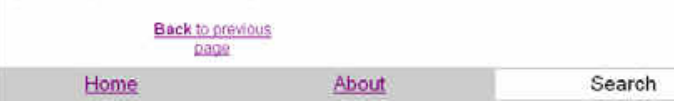

The design team suggested that the search page be a list of all youth groups. The list is categorized so that users can look for specific information, such as group names, locations, and activities as indicated by questionnaire responses.

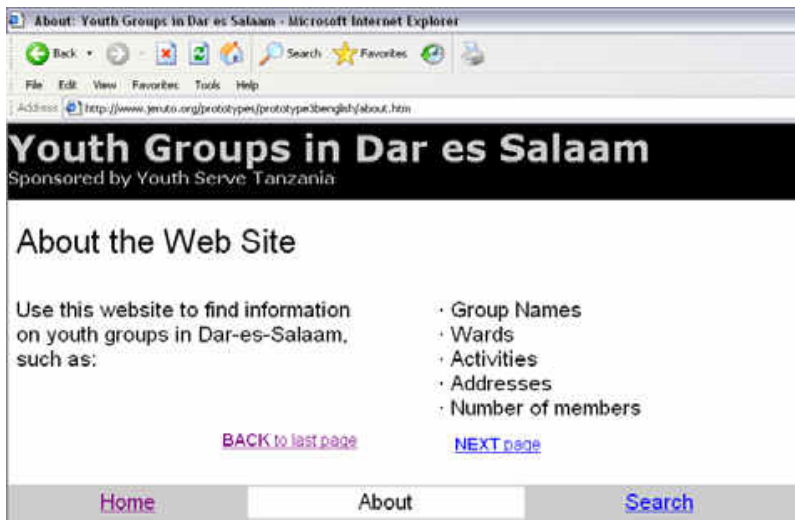

The two options of the search interface in prototype 2 confused users. Though the interface here is not a search, but a list rather, it presents information that Tanzanian students are likely to look for, based on questionnaire responses.

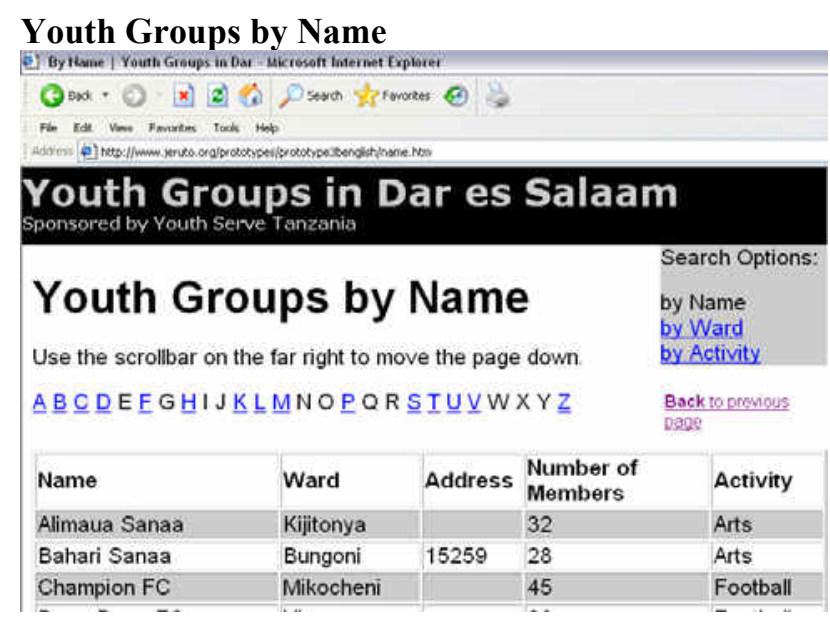

This is one of the pages that intended for users to navigate through during the usability test.

The left-most column in the table is "Name" because this is a page where groups are listed by name. The same is true for every page in the row of alphabetized links.

Each page that displays tables of information on youth groups has the following elements, designed to making reading easier:

- $\quad$ Alternating grey and white table rows

- A text box in the upper-right that gives options for navigating to other lists of youth groups

- A navigation bar below the table, which, on this page, is only visible after scrolling down 
- A row of alphabetized links to pages that list group names and locations alphabetically, or that list groups that perform a certain activity.

- A link, "Back to previous page," that returns the user to the last page visited, behaving like the browser's "Back" button.

Youth Groups by Location (Ward): "B"

This page was intended for users to find during the usability test.

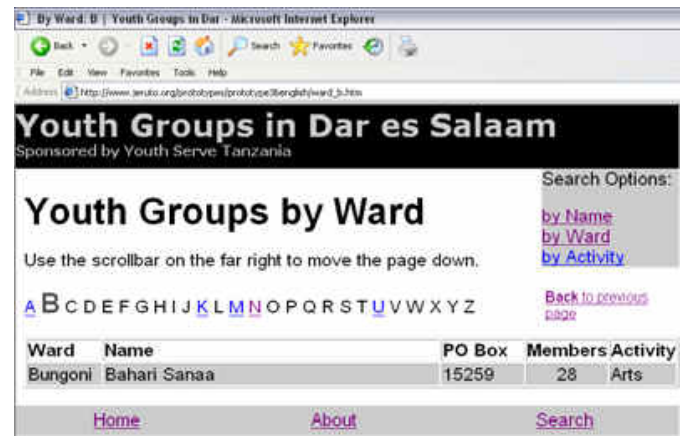

The left-most column in the table is "Ward" because this is a page where groups are listed by location. The letter B in the row of alphabetized links is bold because it is the current page. Other letters in the same row are underlined because they are links to lists of that letter. There are no wards in the database that start with the letters of the underline-free links.

\section{Youth Groups by Activity: "Community"}

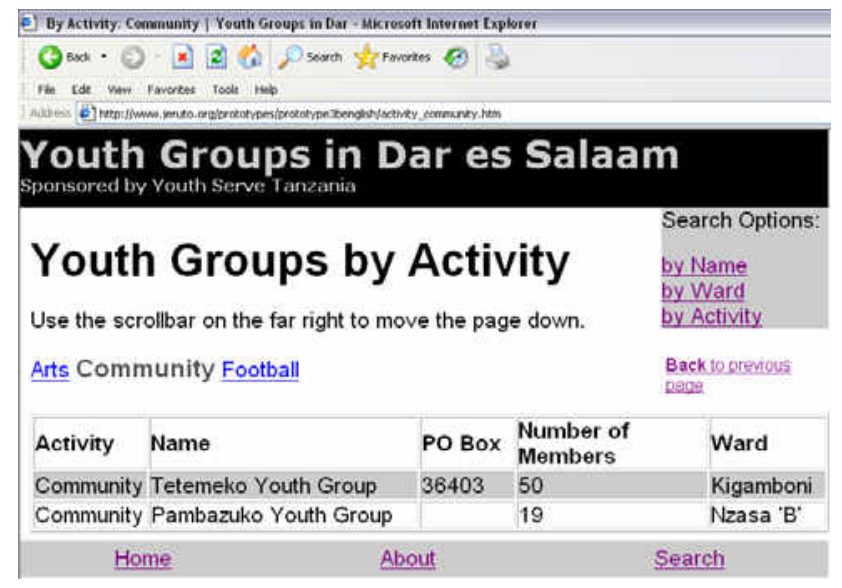

This is one of the pages intended for users to find during the usability test.

The left-most column in the table is "Activity" because this is a page where groups are listed by activity. The word, "Community," in the row of alphabetized links is bold and not underlined because it is the current page 